\title{
Understanding and perceptions of gout: an interdisciplinary assessment among patients, physicians and pharmacists in Italy
}

\author{
L. Punzi' ${ }^{1}$, G. Medea ${ }^{2}$ \\ ${ }^{1}$ Center for Gout and Metabolic Osteoarthropathies, Rheumatology, SS. Giovanni e Paolo Hospital, \\ Venice, Italy; ${ }^{2}$ General Practitioner, Brescia, Italy
}

\begin{abstract}
SUMMARY
The objective was to assess knowledge and therapeutic approaches to the management of gout among healthcare professionals and people with/without gout, in Italy.

This was a cross-sectional internet-based survey targeting general practitioners (GPs), specialists, pharmacists, and people with/without gout. Between December 2017 and March 2018, participants completed questionnaires on epidemiology, cause/risk factors, therapy objectives and management/treatment strategies to improve outcomes.

Overall, 3184 people completed the survey: 699 GPs, 426 specialists, 655 pharmacists and 1404 subjects from the general population: 126 (9.0\%) with and 1278 (91.0\%) without gout. Notably, less than half of GPs, specialists and people without gout confirmed the published $1 \%$ prevalence of gout in Italy. Lifestyle was acknowledged as the main risk factor for gout by nearly $50 \%$ of specialists and GPs, while only $13.8 \%$ and $12.4 \%$, respectively, considered the role of genetic factors. Uric acid overproduction was deemed as the cause of gout by $60 \%$ of GPs and specialists, whereas insufficient excretion by only $30 \%$. Fewer than half of patients were aware that gout permanently damages joints, and even fewer of the renal and cardiovascular implications $(19.4 \%$ and $12 \%$, respectively); moreover, most people without gout replied that their doctor had never talked with them about uric acid and its correlation with gout development. Finally, GPs were divided on uric acid target levels ( $48.3 \%$ said $<6 \mathrm{mg} / \mathrm{dL}$ and $18.9 \%<7 \mathrm{mg} / \mathrm{dL}$ ).

Despite major advances in the knowledge of physiopathological mechanisms of gout, the results of our survey highlight the many treatment and knowledge gaps in its management. Cooperation between multidisciplinary teams is required to break down barriers and ensure optimal treatment with effective and innovative agents of this ever-increasing debilitating condition.
\end{abstract}

Key words: Gout, Italy, multidisciplinary, survey, uric acid-lowering drugs.

Reumatismo, 2020; 72 (1): 31-43

\section{INTRODUCTION}

W hat do English $16^{\text {th }}$ century nobility and the tyrant king of the dinosaurs have in common? Both Henry VIII and Tyrannosaurus Rex reportedly suffered from gout. The former probably because he lived a sedentary, decadent life overindulging in red meat and port wine contaminated with lead. In the latter, the dinosaurian gout recently evidenced in fossilized bones and joints was probably due to the consumption of large quantities of high-purine red meat $(1,2)$. For too long the prevalence and clinical consequences of this debilitating condition have been underestimated $(3,4)$.
Gout is the most common form of inflammatory arthritis in adults and the second most common form of any type of arthritis (5-7). Worldwide, and in particular in developed countries, the prevalence of gout is increasing $(8,9)$. In Italy, gout increased by $36 \%$ in the period 2005-2009 (9-11). Elfishawi et al. reported that not only has the incidence of gout more than doubled over the recent 20 years, but patients diagnosed with gout between 2009 and 2010 had a higher prevalence of comorbid conditions and CV risk factors compared with 19891992 (10).

In Italy, people with gout are managed by both primary and secondary/special- $\overline{\text { Corresponding author: }}$

Leonardo Punzi

Center for Gout

and Metabolic Osteoarthropathies,

Rheumatology, SS Giovanni e Paolo Hospital,

Sst. Castello - 6777 Venice, Italy

E-mail: punzileonardo@gmail.com 
ist healthcare professionals, but still many people do not receive optimal treatment. Education, better diagnosis and effective long-term, multidisciplinary management as well as increased use of preventive strategies are urgently required. To our knowledge, there are no cross-sectional surveys conducted among Italian primary and secondary healthcare professionals and people with/without gout, to assess current knowledge and therapeutic approaches to the management of gout. We devised a crosssectional survey to capture such information, with the overall objective of identifying areas of improvement to ensure gout patients a better clinical outcome.

\section{MATERIALS AND METHODS}

This was a cross-sectional internet-based survey targeting general practitioners, specialists, pharmacists, and people with/ without gout. The healthcare professionals were subscribers to Medikey (an online Italian network), while subjects from the general population were subscribers to 'Dica33', an online platform dedicated to medicine and health. Specialists targeted were rheumatologists, internists, geriatricians, cardiologists, nephrologists, orthopedic consultants and urologists. Subjects from all geographical areas of Italy were invited to participate on a voluntary basis from December 2017 to March 2018. Participants who agreed to take part in the online survey completed a series of multiple-choice questionnaires which differed, based on the target population (see Appendix, Tables A I-V). Respondents were instructed to answer all questions and to select a single reply or multiple responses as indicated. Each of the five questionnaires (GPs, specialists, pharmacists, people with and people without gout) were in turn divided into five major areas - epidemiology, cause/risk factors, objectives of therapy, management and treatment and strategies to improve outcomes. All completed questionnaires were anonymous, and no demographic data were collected.

\section{RESULTS}

Overall, 3184 people completed the questionnaires, out of a total of 137,528 invitations dispatched and 4192 clicks on e-mail, made up of 699 GPs; 426 specialists; 655 pharmacists; 1404 citizens (1278 people without gout and 126 patients with gout) (Table I).

There were no significant differences in percentage of responses from the seven categories of specialists (rheumatologists, internists, geriatricians, cardiologists, nephrologists, orthopedic consultants and urologists). Responders were from seven regions of Northern Italy, seven from Central Italy and six from the South and Islands, with no major differences in the mean response for the three macro areas (North, Center, South and Islands) between the five groups studied (GPs, specialists, pharmacists, people with and people without gout). There was a trend towards higher response rates in subjects from Val d'Aosta: $100 \%$ of citizens (with/without gout) replied while none from Molise replied.

\section{Epidemiology}

In total, 58\% of GPs and specialists acknowledged the fact that gout prevalence was increasing, with $34 \%$ of GPs and

Table I - Participants in survey.

\begin{tabular}{|l|c|c|c|c|c|}
\hline Target group & $\begin{array}{c}\text { Invitations } \\
\text { e-mailed }\end{array}$ & $\begin{array}{c}\text { Clicks } \\
\text { on e-mail }\end{array}$ & $\begin{array}{c}\text { Questionnaires } \\
\text { completed }\end{array}$ & $\begin{array}{c}\text { \% participation } \\
\text { in survey of those } \\
\text { invited }\end{array}$ & $\begin{array}{c}\text { \% participation } \\
\text { in survey of those who } \\
\text { clicked on e-mail }\end{array}$ \\
\hline General practitioners & 29,456 & 885 & 699 & 2 & 79 \\
\hline Specialists & 27,334 & 729 & 426 & 2 & 58 \\
\hline Pharmacists & 29,153 & 750 & 655 & 2 & 87 \\
\hline Citizens & 51,585 & 1,828 & 1,404 & 3 & 77 \\
\hline
\end{tabular}


$37.5 \%$ of specialists aware of published data on $1 \%$ published prevalence in Italy, information shared also by $42 \%$ of people without gout.

\section{Cause/risk factors}

Over $70 \%$ of people without gout defined it as a painful inflammation of the joints and $88.5 \%$ of patients with gout said it was due to high levels of uric acid in the blood (hyperuricemia).

When asked about risk factors, $50 \%$ of both specialists and GPs said the main risk factor for gout was lifestyle (consumption of a diet with high purine content, excessive consumption of alcohol, etc.) with 33\% and $30 \%$ of specialists and GPs saying it was the presence of co-morbidities (metabolic syndrome, chronic renal failure, etc.). Only $12 \%$ of GPs and $14 \%$ of specialists considered genetic factors played a role. Overall $61 \%$ of GPs and $65 \%$ of specialists replied that it was caused by overproduction of uric acid and $33 \%$ and $30 \%$ of GPs and specialists, respectively, reported that it was caused by insufficient excretion (Figure 1).

\section{Patients with gout: knowledge of their condition}

Less than half of patients with gout (44.6\%) knew that gout could result in permanent damage to the joints and $19.4 \%$ and $12 \%$ were aware of the renal and cardiovascular implications, respectively. To learn more about their conditions, $65.5 \%$ would approach their GP, $18 \%$ a specialist, $1.4 \%$ their pharmacist and $15 \%$ would try to find out information from other sources (internet). They would like to receive information on a range of subjects from the causes of gout to its long-term consequences, how to adapt lifestyle and what are the available therapies. Pharmacists who interface with gout patients confirmed that patients are not aware of the seriousness of gout and as a result, they underestimate the impact of the disease.

\section{Objectives of therapy}

Nearly $80 \%$ of specialists reported that measuring serum uric levels (sUA) was the principal method to determine efficacy of therapy (Figure 2A). GPs were divided on the target levels of UA on gout treatment:

\section{SPECIALISTS AND GENERAL PRACTITIONERS}

In your opinion what are the main risk factors for hyperuricaemia in patients with gout?

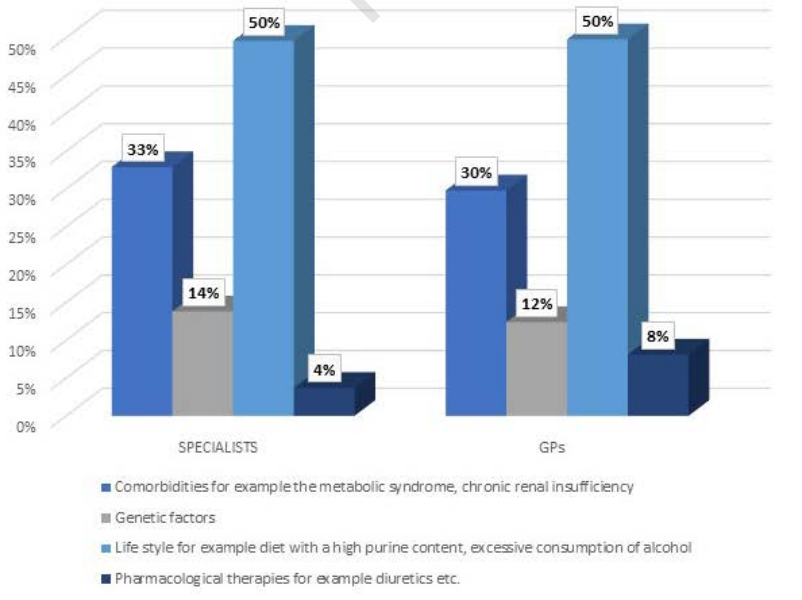

Overproduction and insufficient excretion of uric acid are the causes of hyperuricaemia. Which is in your opinion the predominant cause?

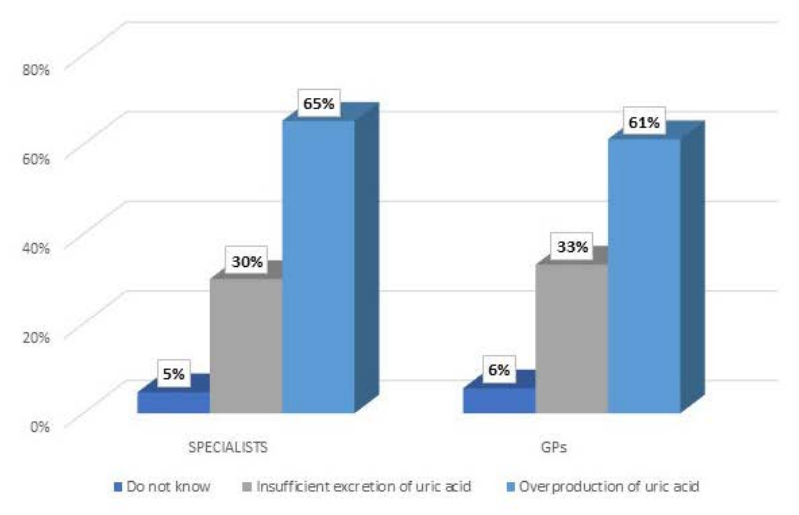

Figure 1 - Responders to questions on cause/risk factors of gout (specialists and GPs). 


\section{SPECIALISTS}

In your clinical practice what are the main therapeutic targets on which you determine the efficacy of treatment?

\section{GENERAL PRACTITIONERS}

What are the target levels of uric acid in the treatment of hyperuricaemia in patients with gout?
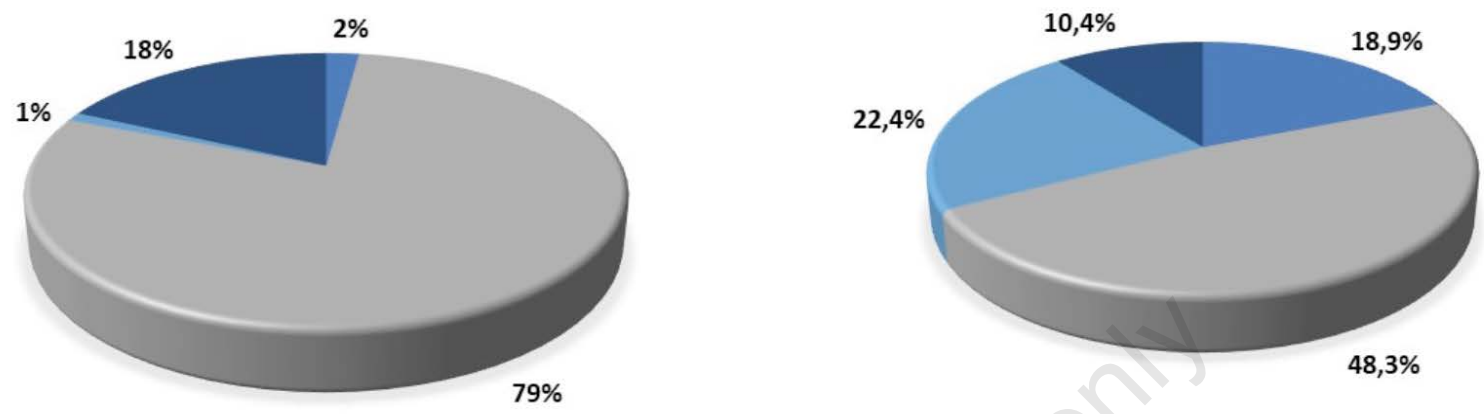

Screening for example echography, to determine the presence of uric acid crystals

a Regular measurement of uricemia

Q Reduction in the dimensions of tophi

Reduction in the frequency of acute attacks.

Figure 2 - A and B) Responders to questions on therapeutic targets/objectives of therapy (GPs, specialists).

the majority said $<6 \mathrm{mg} / \mathrm{dL}(48.3 \%)$, with $18.9 \%$ replying $<7 \mathrm{mg} / \mathrm{dL}$ (Figure $2 \mathrm{~B}$ ).

\section{Management and treatment}

Most GPs and specialists acknowledged the importance of monitoring sUA levels, especially in patients with other comorbidities. Almost all GPs reported that measurement of sUA should be done routinely at least once a year, with 50\% linking the need of measuring it to the presence of $\mathrm{CV}$ diseases or kidney function impairment. This was also reflected in patients' answers on the time interval since the last sUA measurement: the majority $(61 \%)$ referred that they had had an sUA measurement within the past 6 months.

GPs and specialists agreed that the main limitations of gout treatments were (in order of relevance): low compliance to therapy, side effects, pharmacological interactions and low efficacy in reaching therapeutic targets. With regard to pharmacists' involvement in gout management, only a minority of them $(30 \%)$ reported to be involved in gout management and then only at the request of the patient. Over 50\% acknowledged that the main limit to proper management is adherence to therapy, but over $40 \%$ believed that therapy can be interrupted if the patient is symptom free for $>12$ months.

Incomplete/lack of knowledge has also an impact on gout management: $49 \%$ of patients with gout say they take continuous therapy, with $27 \%$ stating they take medication when they have an attack/flare-up. Of note, nearly $70 \%$ of people without gout reported that their doctor had never talked with them about UA levels (Figure 3).

\section{Strategies to improve outcomes}

Patients would like to receive more information on: the causes of their disease (23\%), long-term consequence of gout (25\%), recommended modifications in lifestyle (24\%) and treatment options $(27 \%)$. Overall, $50 \%$ of specialists and $52.8 \%$ of GPs considered that it was necessary to improve training for doctors to promote knowledge of the latest guidelines on the management and treatment of gout and provide more information to 
patients (for example on how to improve adherence).

Over $20 \%$ of both groups highlighted the importance of greater co-operation between GPs and specialists (Figure 4). Pharmacists $(36.9 \%)$ believe that the disease is underestimated and that people with gout require more information on how to adapt their lifestyle.

\section{DISCUSSION AND CONCLUSIONS}

Gout is a crystal deposition disease resulting from hyperuricemia and associated with a wide spectrum of articular, cardiovascular $(\mathrm{CV})$, renal and metabolic complications, as well as an increased risk of mortality (3, 4). Hyperuricemia results

\section{GENERAL PRACTITIONERS}

What do you think of uric acid monitoring?

\section{PEOPLE WITHOUT GOUT}

Has your doctor ever discussed with you uric acid levels in blood and risk of gout?

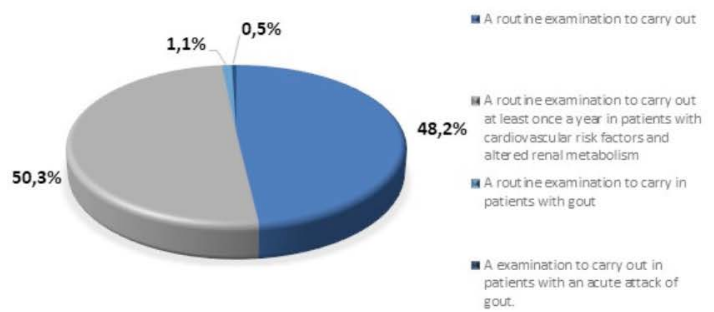

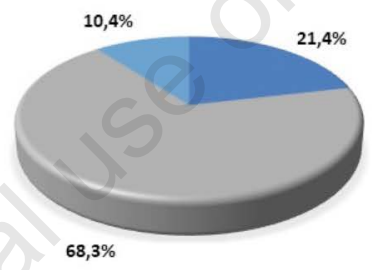

QYes, my doctor has discussed the importance of keeping uric acid levels under control and No, my doctor has never. discussed uric acid

\section{PEOPLE WITH GOUT}

When was the last time you had your uric acid levels measured?

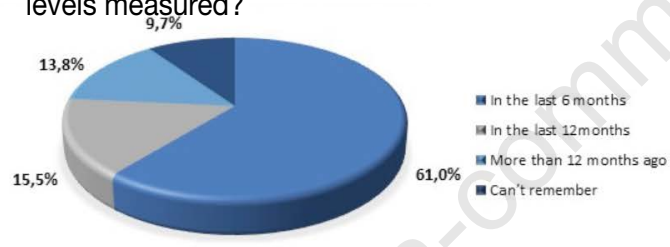

When do you take treatment?

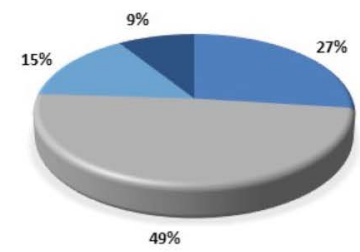

anily when I have an a ute atack acid levels.

a I take therapy to lower uricemia but only occasionally - Don't know if therapy I take is to

\section{SPECIALISTS AND GENERAL PRACTITIONERS}

In your experience what are the main limitations in the treatment with currently available drugs?

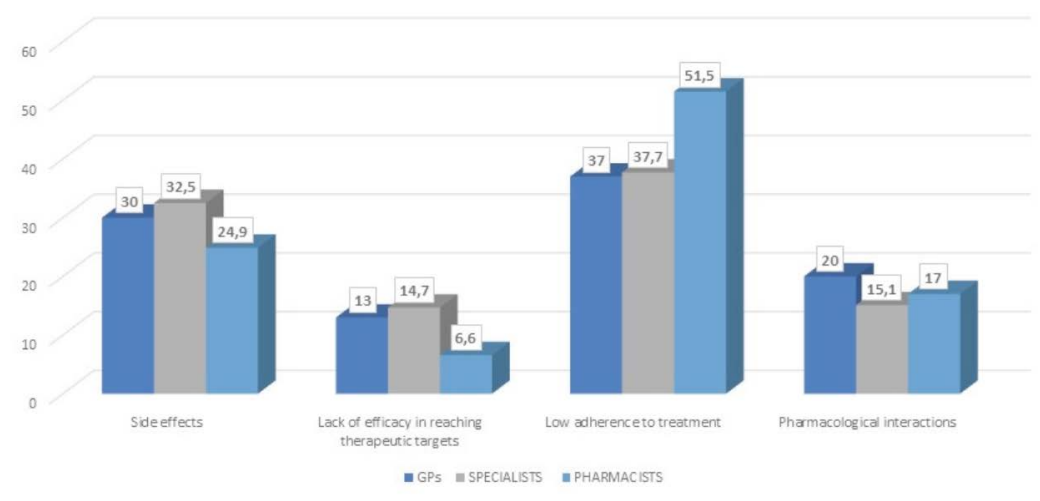

Figure 3 - Responses to questions on management and treatment of gout (GPs, specialists, people with/without gout). 


\section{PHARMACISTS}

Do you think gout is.
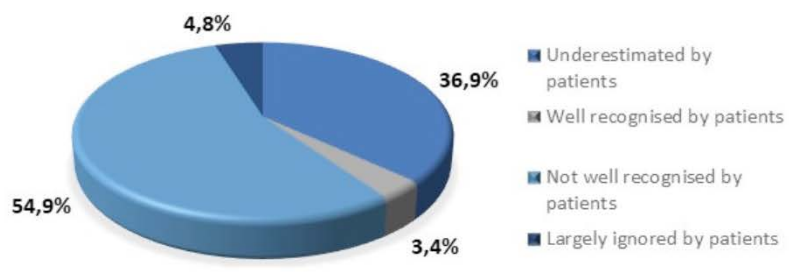

What information should the general population in your experience be supplied about gout?

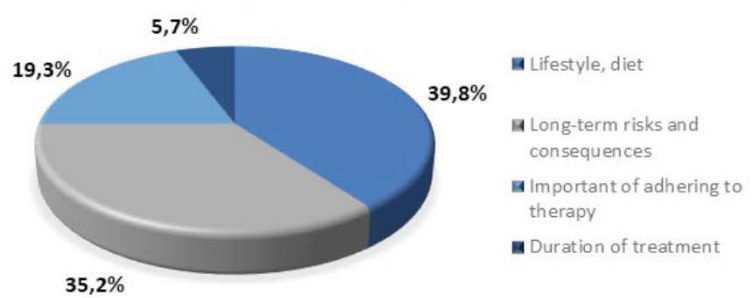

SPECIALISTS AND GENERAL PRACTITIONERS

If you agree that gout is underestimated - what strategies would you propose to raise awareness and treatment?
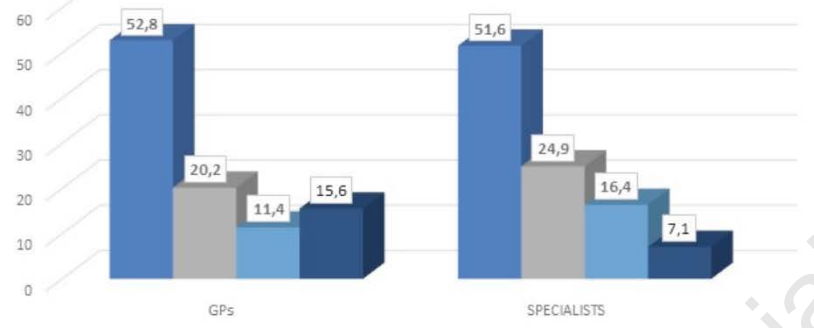

- Training for doctors on current guicelines and improwing

information for patients on for ex ample improving adherence.

- Better cooper ation between general practitioners and specialists

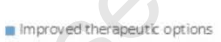

- I do not think gout is underestimated

Figure 4 - Responders to questions on strategies to improve outcomes (GPs, specialists, pharmacists).

from the overproduction of urate (around $10 \%$ ), the underexcretion of urate (around $90 \%$ ) and often from a combination of the two $(12,13)$. Clinical signs of gout develop after long-standing hyperuricemia but the process of silent deposition of monosodium urate (MSU) can occur long before symptoms emerge. There is a growing body of evidence supporting the hypothesis that morpho-structural changes preceding clinical manifestation induced by hyperuricemia, can occur in both intra- and extraarticular structures and persistent hyperuricemia may cause a range of subclinical skeletal changes in asymptomatic individuals (14). Silent deposition of MSU crystals in patients with asymptomatic hyperuricemia has been associated with more severe coronary calcification, indicating more severe coronary artery disease in relation to crystal deposition and a poorer prognosis (15). Serum UA levels above its saturation point $(\sim 6.8 \mathrm{mg} / \mathrm{dL}, 0.41 \mathrm{mmol} / \mathrm{L})$ result in the deposition of MSU crystals. These deposits, spontaneously or as a result of a stressful event, can be destabilized and lead to shedding of crystals which generates an inflammatory response leading to an acute attack of arthritis and, in the long term, to tophi formation. MSU crystal deposits go on to cause irreversible bone erosion, chronic pain, impaired joint function and a drastic reduction in quality of life. If not treated appropriately, gout develops into a condition called chronic tophaceous gout, characterized by continuous pain, involvement of more joints and presence of tophi in the extra-articular tissues, leading to progressive decrease of joint function and permanent joint damage (3). A body of evidence now shows a strong association between hyperuricemia and new onset/ progression of cardio-nephro-metabolic complications, along with increased risk of mortality $(8,16,17)$.

A recent post hoc analysis of the multinational EURIKA study in over 7500 patients supported the role of sUA as a risk factor for cardiometabolic diseases, with higher sUA levels associated with progressively 
higher 10-year CV death risk score in patients with at least one $\mathrm{CV}$ risk factor but no CV disease (18). Furthermore, there is evidence that UA is a strong risk factor for myocardial infarction and stroke (19): notably, it has been shown that a relation between sUA levels and CVD already exists in patients with sUA levels considered as normal to high, i.e. $>5.2-5.5 \mathrm{mg} / \mathrm{dL}$ (19). Although additional evidence is required to draw definitive conclusions, these data suggest the need for prompt therapeutic interventions to improve symptoms and reduce the risk of associated comorbidities. The therapeutic goal in the management of hyperuricemia associated with gout, is to lower sUA levels to a threshold value of $<6.0 \mathrm{mg} / \mathrm{dL}(<360 \mu \mathrm{mol} / \mathrm{L})$ or $<5 \mathrm{mg} / \mathrm{dL}$ in more severe conditions $(<300 \mu \mathrm{mol} / \mathrm{L})$ (20-23).

Despite these major advances in our understanding of the pathophysiology of gout and the availability of effective treatments, current management remains suboptimal. Reasons for this include poor diagnostic procedures, physicians not regularly measuring sUA levels, poor compliance and incorrect dosage of urate-lowering therapies (ULT). Compliance is a major problem, with an Italian study reporting $17 \%$ of patients as adherent to treatment after 3 months of therapy (24), while Perez-Ruiz $\&$ Desideri reported that adherence to treatment was less than $40 \%$ in the first year of therapy $(25,26)$.

The results of our cross-sectional Internet survey on gout provide much needed data on this neglected but debilitating condition. Despite major advances in effective therapies for the management of gout, there are still many treatment and knowledge gaps in its management. To this end, ours was a far-reaching and ambitious study focused on specialists, GPs and people with/without gout, with the aim of capturing their opinions and knowledge. To our knowledge this is one of the largest studies of this nature carried out in Italy, with data collected from over 3000 subjects. Of the 1404 citizens who responded to our survey, 9\% had gout and although this cannot be interpreted as a reflection of the real preva- lence of the disease at a national level, it can be considered a red flag indicating that gout is still significantly under-reported and, therefore, under-treated. Gout is still considered to be an ancient disease, as demonstrated by the fact that around $40 \%$ of healthcare professionals (HCPs) were not aware that gout's prevalence in Italy is progressively increasing (9). Almost half of specialists said the main risk factor for gout was lifestyle, with a small percentage of GPs (12.4\%) and of specialists (13.8\%) reporting that genetic factors played a role. Indeed, around $60 \%$ of GPs and specialists considered high-purine diet and lifestyle the main reasons for overproduction of uric acid and only $30 \%$ imputed hyperuricemia to insufficient renal excretion.

These data highlight the need to increase awareness among HCPs on the underlying causes of hyperuricemia and gout, in order to ensure a more effective and physiological approach to its management. In the last decade, a treat-to-target (T2T) approach has been proposed for gout with much discussion on what the target should be. Therapeutic targets endorsed by EULAR, ACR and other scientific societies consider $6 \mathrm{mg} / \mathrm{dL}(0.36 \mathrm{mmol} / \mathrm{L})$ as the minimum cut-off to obtain meaningful benefit from ULT, whereas $5 \mathrm{mg} / \mathrm{dL}(0.30 \mathrm{mmol} / \mathrm{L})$ is considered the minimum target in patients suffering from more severe clinical characteristics (27).

In everyday clinical practice, there is still no common recognition of the UA safety target level, a situation made more difficult by the fact that laboratories refer to normal ranges defined according to the distribution in the healthy population (3.5-7.2 $\mathrm{mg} / \mathrm{dL})$, regardless of the defined safety threshold of $6 \mathrm{mg} / \mathrm{dL}$. Lately, based on evidence showing a relation between sUA levels >5.2-5.5 mg/dL and CVD, HCPs are becoming more aware of the need to maintain sUA levels lower than $6 \mathrm{mg} / \mathrm{dL}$. This was reflected in our study, where around $48 \%$ of GPs considered target levels values should be $<6 \mathrm{mg} / \mathrm{dL}$ and $22.4 \%$ said they should be $<5 \mathrm{mg} / \mathrm{dL}$ As the causes of hyperuricemia are twofold (overproduction and underexcretion), to 
ensure a physiological approach to treatment of hyperuricemia and to ensure T2T levels are met, both these mechanisms should be targeted. Xanthine oxidase inhibitors (XOI, i.e. first-line agent allopurinol and second-line febuxostat) target only UA production and as a result it is difficult to reach target levels and many patients are classified as non-responders to XOI alone. Based on this rationale, lesinurad, a new selective uricosuric acting on renal underexcretion, has been introduced into clinical practice; inhibiting URAT1 and OAT4 renal transporters, lesinurad increases uric acid excretion and thereby lowers sUA. When used in combination with allopurinol or febuxostat, it provides a dual mechanism approach that lowers sUA more effectively compared to XOI monotherapy. This strategy is supported by current EULAR guidelines recommending a second-line combination therapy with allopurinol and a uricosuric agent in patients who do not achieve the sUA target with XOI monotherapy, given the complementary mechanism of action of these molecules (21).

The majority of GPs and specialists in our study agreed that one of the limitations of gout treatment is low compliance to therapy, with only $49 \%$ of patients reporting they take continuous therapy and nearly $30 \%$ only taking their medication when they have an attack/flare-up. The T2T approach requires a concerted effort to optimize treatment and management of gout at the patient, community and national level, in order to increase awareness of the condition with the ultimate aim of increasing adherence and hence the effectiveness of therapy.

The WHO defined adherence as a multidimensional phenomenon determined by the interplay of five sets of factors/dimensions (social and economic, health system, therapy-related, patient-related, conditionrelated), of which patient-related factors are just one determinant (28). The common belief that patients are solely responsible for taking their treatment is misleading and most often reflects a misunderstanding of how other factors affect people's behavior and capacity to adhere to their treatment. This is reflected in our results, as nearly $70 \%$ of people without gout replied that their doctor had not proactively talked with them about UA levels.

Given that well-tolerated and effective treatments for gout are now available, improving adherence to therapy requires overcoming patient- and physician-related barriers and education. Therefore, cooperation between all involved parties (patients, HCPs and pharmacists) is essential to overcome difficulties and ensure optimal management.

Our study is not without its limitations in that it enrolled patients (and specialists) who were already registered on Italian medicine/health sites and as such may have constituted a degree of selection bias. Nevertheless, our results highlight the many treatment and knowledge gaps in the management of gout in Italy. They show that cooperation between multidisciplinary teams and improved education is required to break down barriers and ensure optimal treatment of this ever-increasing, debilitating condition.

\section{Acknowledgements}

The authors would like to thank all participants in the study, Grünenthal for the below mentioned support and EDRA for carrying out the logistical aspects of the survey and for editorial support.

\section{Contributions}

Both authors contributed to the research, development and writing of the manuscript.

\section{Conflicts of interest}

LP reports consulting fees, speaker fees or grants from: Abbvie, Fidia, Grünenthal, Menarini, Pfizer, MSD, BMS. GM reports consulting fees from Grünenthal, AstraZeneca.

\section{Funding}

This survey has been conducted with the support of Grünenthal, both for content ideation and target identification. The costs for carrying out the survey and for data publication were also funded by Grünenthal. 


\section{APPENDIX}

Table A I - Questionnaire aimed at GPs.

\begin{tabular}{|c|c|}
\hline Question & Answer \\
\hline \multirow{4}{*}{$\begin{array}{l}\text { EPIDEMIOLOGY? } \\
\text { Indicate which of the following you agree with? } \\
\text { Select one reply }\end{array}$} & In Italy the number of patients with gout is decreasing \\
\hline & $\begin{array}{l}\text { The prevalence of gout in Italy is very low } \\
\text { (around } 0.1 \% \text { of the population) }\end{array}$ \\
\hline & In Italy the number of patients with gout is increasing \\
\hline & Gout today affects $0.1 \%$ of Italians \\
\hline \multirow{4}{*}{$\begin{array}{l}\text { RISK FACTORS/CAUSE } \\
\text { In your opinion what are the main risk factors } \\
\text { for hyperuricemia in patients with gout? } \\
\text { Select one reply }\end{array}$} & Genetic factors \\
\hline & Pharmacological therapies for example diuretics etc. \\
\hline & $\begin{array}{l}\text { Comorbidities for example the metabolic syndrome, } \\
\text { chronic renal insufficiency. }\end{array}$ \\
\hline & $\begin{array}{l}\text { Lifestyle for example diet with a high purine content, } \\
\text { excessive consumption of alcohol. }\end{array}$ \\
\hline \multirow{3}{*}{$\begin{array}{l}\text { RISK FACTORS/CAUSE } \\
\text { Overproduction and insufficient excretion } \\
\text { of uric acid are the causes of hyperuricemia. } \\
\text { Which is in your opinion the predominant } \\
\text { cause? } \\
\text { Select one reply }\end{array}$} & Overproduction of uric acid \\
\hline & Insufficient excretion of uric acid \\
\hline & Don't know \\
\hline \multirow{4}{*}{$\begin{array}{l}\text { THERAPEUTIC TARGET } \\
\text { What are the target levels of uric acid } \\
\text { in the treatment of hyperuricemia in patients } \\
\text { with gout? } \\
\text { Select one reply }\end{array}$} & $<7 \mathrm{mg} / \mathrm{dL}$ \\
\hline & $<6 \mathrm{mg} / \mathrm{dL}$ \\
\hline & $<5 \mathrm{mg} / \mathrm{dL}$ \\
\hline & $<4 \mathrm{mg} / \mathrm{dL}$ \\
\hline \multirow{4}{*}{$\begin{array}{l}\text { MANAGEMENT AND TREATMENT } \\
\text { Uric acid monitoring in your opinion is? } \\
\text { Select one reply }\end{array}$} & $\begin{array}{l}\text { A routine examination to be carried out at least once } \\
\text { a year on all patients }\end{array}$ \\
\hline & $\begin{array}{l}\text { A routine examination to be carried out at least once } \\
\text { a year on patients with cardiovascular risk factors } \\
\text { and altered renal metabolism }\end{array}$ \\
\hline & $\begin{array}{l}\text { A routine examination to be carried out on patients } \\
\text { with gout }\end{array}$ \\
\hline & $\begin{array}{l}\text { An examination to be carried out on patients with a } \\
n \text { acute attack of gout. }\end{array}$ \\
\hline \multirow{4}{*}{$\begin{array}{l}\text { MANAGEMENT AND TREATMENT } \\
\text { In your experience what are the main } \\
\text { limitations in the treatment of hyperuricemia } \\
\text { with currently available drugs? } \\
\text { Select more than one reply as appropriate }\end{array}$} & Side effects \\
\hline & Lack of efficacy in reaching therapeutic targets \\
\hline & Low adherence to treatment \\
\hline & Pharmacological interactions \\
\hline \multirow{4}{*}{$\begin{array}{l}\text { STRATEGIES TO IMPROVE OUTCOMES } \\
\text { If you agree that gout is underestimated - } \\
\text { what strategies would you propose to raise } \\
\text { awareness and treatment? } \\
\text { Select more than one reply as appropriate }\end{array}$} & $\begin{array}{l}\text { Training for doctors on current guidelines and } \\
\text { improving information for patients on for example } \\
\text { improving adherence }\end{array}$ \\
\hline & $\begin{array}{l}\text { Better cooperation between general practitioners } \\
\text { and specialists }\end{array}$ \\
\hline & Improved therapeutic options \\
\hline & I do not think gout is underestimated \\
\hline
\end{tabular}


Table A II - Questionnaire aimed at specialists.

\begin{tabular}{|c|c|}
\hline Question & Answers \\
\hline \multirow{3}{*}{$\begin{array}{l}\text { EPIDEMIOLOGY } \\
\text { Indicate which of the following you agree with? } \\
\text { Select one reply }\end{array}$} & $\begin{array}{l}\text { The prevalence of gout in Italy is very low } \\
\text { (around } 0.1 \% \text { of the population) }\end{array}$ \\
\hline & In Italy the number of patients with gout is increasing \\
\hline & Gout today affects $0.1 \%$ of Italians \\
\hline \multirow{4}{*}{$\begin{array}{l}\text { RISKFACTORS/CAUSE } \\
\text { In your opinion what are the main risk factors } \\
\text { for hyperuricemia in patients with gout? } \\
\text { Select one reply }\end{array}$} & $\begin{array}{l}\text { Comorbidities for example the metabolic syndrome, } \\
\text { chronic renal insufficiency }\end{array}$ \\
\hline & Genetic factors \\
\hline & $\begin{array}{l}\text { Life style for example diet with a high purine content, } \\
\text { excessive consumption of alcohol }\end{array}$ \\
\hline & Pharmacological therapies for example diuretics etc. \\
\hline \multirow{3}{*}{$\begin{array}{l}\text { RISKFACTORS/CAUSE } \\
\text { Overproduction and insufficient excretion } \\
\text { of uric acid are the causes of hyperuricemia. } \\
\text { Which is in your opinion the predominant } \\
\text { cause? } \\
\text { Select one reply }\end{array}$} & Insufficient excretion of uric acid \\
\hline & Do not know \\
\hline & Overproduction of uric acid \\
\hline \multirow{4}{*}{$\begin{array}{l}\text { THERAPEUTIC TARGETS } \\
\text { In your clinical practice what are the main } \\
\text { therapeutic targets on which you determine } \\
\text { the efficacy of treatment? } \\
\text { Select one reply }\end{array}$} & $\begin{array}{l}\text { Screening for example echography, to determine } \\
\text { the presence of uric acid crystals } \\
\end{array}$ \\
\hline & Regular measurement of uricemia \\
\hline & Reduction in the dimensions of tophi \\
\hline & Reduction in the frequency of acute attacks. \\
\hline \multirow{4}{*}{$\begin{array}{l}\text { MANAGEMENT AND TREATMENT } \\
\text { In your experience what are the main } \\
\text { limitations in the treatment of hyperuricemia } \\
\text { with currently available products? } \\
\text { Select more than one reply as appropriate }\end{array}$} & Side effects \\
\hline & Lack of efficacy in reaching therapeutic targets \\
\hline & Low adherence to treatment \\
\hline & Pharmacological interactions \\
\hline \multirow{4}{*}{$\begin{array}{l}\text { IMPACT OF CONDITION } \\
\text { In your clinical experience what effect } \\
\text { does gout have on a patient's quality of life - } \\
\text { range on a scale of } 1 \text { (minimal impact) } \\
\text { to } 4 \text { (maximal impact) } \\
\text { Select one reply }\end{array}$} & 1 \\
\hline & 2 \\
\hline & 3 \\
\hline & 4 \\
\hline \multirow{4}{*}{$\begin{array}{l}\text { STRATEGIES TO IMPROVE OUTCOMES } \\
\text { If you agree that gout is underestimated - } \\
\text { what strategies would you propose to raise } \\
\text { awareness and treatment? } \\
\text { Select more than one reply as appropriate }\end{array}$} & $\begin{array}{l}\text { Training for doctors on current guidelines and improving } \\
\text { information for patients on for example improving adherence }\end{array}$ \\
\hline & $\begin{array}{l}\text { Better cooperation between general practitioners } \\
\text { and specialists }\end{array}$ \\
\hline & Improved therapeutic options \\
\hline & I do not think gout is underestimated \\
\hline
\end{tabular}


Table A III - Questionnaire aimed at pharmacists

\begin{tabular}{|c|c|}
\hline Question & Answers \\
\hline \multirow{4}{*}{$\begin{array}{l}\text { STRATEGIES TO IMPROVE OUTCOMES } \\
\text { Do you think gout is? } \\
\text { Select one reply }\end{array}$} & Underestimated by patients \\
\hline & Well recognized by patients \\
\hline & Not well recognized by patients \\
\hline & Largely ignored by patients \\
\hline \multirow{4}{*}{$\begin{array}{l}\text { STRATEGIES TO IMPROVE OUTCOMES } \\
\text { What information should the general population in your } \\
\text { experience be supplied with about gout? } \\
\text { Select more than one reply as appropriate }\end{array}$} & Lifestyle, diet \\
\hline & Long-term risks and consequences \\
\hline & Important of adhering to therapy \\
\hline & Duration of treatment \\
\hline \multirow{4}{*}{$\begin{array}{l}\text { MANAGEMENT AND TREATMENT } \\
\text { You have a patient receiving chronic treatment with drugs } \\
\text { to reduce uric acid levels (allopurinol or febuxostat). Do you } \\
\text { ask if he/she has had a recent check of uric acid levels? } \\
\text { Select one reply }\end{array}$} & Always \\
\hline & Only if the patient raises it \\
\hline & Sometimes \\
\hline & $\infty \times$ \\
\hline \multirow{4}{*}{$\begin{array}{l}\text { MANAGEMENT AND TREATMENT } \\
\text { In patients with gout receiving treatment to reduce } \\
\text { uric acid levels (allopurinol or febuxostat) which of the } \\
\text { following statements do you agree with? } \\
\text { Select one reply }\end{array}$} & Treatment can be interrupted in the prolonged absence of symptoms (>12 months) \\
\hline & Treatment can be stopped when acute attacks of gout occur \\
\hline & Treatment should provide prophylaxis for the first months of therapy \\
\hline & Treatment must be continued for life \\
\hline \multirow{4}{*}{$\begin{array}{l}\text { MANAGEMENT AND TREATMENT } \\
\text { In your experience what are the main limitations in the } \\
\text { treatment of hyperuricemia with currently available drugs? } \\
\text { Select more than one reply as appropriate }\end{array}$} & Side effects \\
\hline & Lack of efficacy in reaching therapeutic targets \\
\hline & Low adherence to treatment \\
\hline & Pharmacological interactions \\
\hline
\end{tabular}

Table A IV - Questionnaire aimed at patients without gout.

\begin{tabular}{|c|c|}
\hline Question & Answer \\
\hline Have you ever been diagnosed with gout? & If no continue with questions below \\
\hline \multirow{4}{*}{$\begin{array}{l}\text { CAUSE } \\
\text { What is gout? } \\
\text { Select one reply }\end{array}$} & It is a painful form of inflammation of the joints \\
\hline & It is a skin condition \\
\hline & It is a form of diabetes \\
\hline & I don't know \\
\hline \multirow{4}{*}{$\begin{array}{l}\text { EPIDEMIOLOGY } \\
\text { Do you think gout ...? } \\
\text { Select more than one reply as appropriate }\end{array}$} & Affects more men than women \\
\hline & Affects 1 in 100 Italians and the numbers affected are increasing yearly \\
\hline & Is an uncommon form or inflammatory arthritis \\
\hline & The number of patients affected is decreasing in Italy \\
\hline \multirow{4}{*}{$\begin{array}{l}\text { RISK FACTORS } \\
\text { What factors increase the risk of gout } \\
\text { Select more than one reply as appropriate }\end{array}$} & High level of uric acid in the blood (hyperuricemia) \\
\hline & Proven cases of gout in family \\
\hline & Obesity, hypertension, diabetes and renal conditions. \\
\hline & Diet containing high levels of protein (mean, shellfish, alcohol) \\
\hline \multirow{4}{*}{$\begin{array}{l}\text { MANAGEMENT AND TREATMENT } \\
\text { Which of the following do you measure regularly for } \\
\text { general health? } \\
\text { Select more than one reply as appropriate }\end{array}$} & Blood pressure \\
\hline & Cholesterol \\
\hline & Uric acid \\
\hline & Glucose (blood sugar levels) \\
\hline \multirow{3}{*}{$\begin{array}{l}\text { MANAGEMENT AND TREATMENT } \\
\text { Has your doctor ever discussed with you uric acid levels } \\
\text { in blood and risk of gout? } \\
\text { Select one reply }\end{array}$} & $\begin{array}{l}\text { Yes, my doctor has discussed the importance of keeping uric acid levels under } \\
\text { control and the risk of developing gout }\end{array}$ \\
\hline & No, my doctor has never discussed uric acid \\
\hline & I don't know/Don't remember \\
\hline
\end{tabular}


Table A V - Questionnaire targeting patients with gout.

\begin{tabular}{|c|c|}
\hline Question & Answer \\
\hline Have you ever been diagnosed with gout? & If yes continue with questions below \\
\hline \multirow{4}{*}{$\begin{array}{l}\text { CAUSE } \\
\text { What are the most important causes of gout? } \\
\text { Select one reply }\end{array}$} & High level of uric acid in the blood (hyperuricemia) \\
\hline & High level of glucose in the blood (hyperglycemia) \\
\hline & High level of cholesterol in the blood (hypercholesterolemia) \\
\hline & Bad lifestyle (poor diet feeding, lack of exercise, etc.) \\
\hline \multirow{4}{*}{$\begin{array}{l}\text { KNOWLEDGE OF CONDITION } \\
\text { If not treated gout can cause ... } \\
\text { Select more than one reply as appropriate }\end{array}$} & Permanent damage to the joints \\
\hline & Kidney stones \\
\hline & Cardiovascular conditions \\
\hline & All of the above \\
\hline \multirow{4}{*}{$\begin{array}{l}\text { MANAGEMENT AND TREATMENT } \\
\text { When was the last time you had your uric acid } \\
\text { levels measured? } \\
\text { Select one reply }\end{array}$} & In the last 6 months \\
\hline & In the last 12 months \\
\hline & More than 12 months ago \\
\hline & Can't remember \\
\hline \multirow{4}{*}{$\begin{array}{l}\text { KNOWLEDGE OF CONDITION } \\
\text { If you need information on gout who do you } \\
\text { normally ask? } \\
\text { Select more than one reply as appropriate }\end{array}$} & Family doctor \\
\hline & Specialist \\
\hline & Pharmacist \\
\hline & I search for information myself for example on the internet \\
\hline \multirow{4}{*}{$\begin{array}{l}\text { KNOWLEDGE OF CONDITION } \\
\text { On what areas of gout would you like to have } \\
\text { more information? } \\
\text { Select more than one reply as appropriate }\end{array}$} & Causes of the condition \\
\hline & Long-term consequences of the condition. \\
\hline & Change in life style \\
\hline & Available therapies \\
\hline \multirow{4}{*}{$\begin{array}{l}\text { MANAGEMENT AND TREATMENT } \\
\text { When do you take treatment? } \\
\text { Select one reply }\end{array}$} & Only when I have an acute attack \\
\hline & I take it continuously to reduce uric acid levels \\
\hline & I take therapy to lower uricemia but only occasionally \\
\hline & Don't know if the therapy I take is to lower uric acid levels \\
\hline
\end{tabular}

\section{REFERENCES}

1. Rothschild BM, Tanke D, Carpenter K. Tyrannosaurs suffered from gout. Nature. 2019; 387: 357 .

2. Ceccarelli G. Archeology in medicine: digging up into the tophi of Popes, Dukes and Kings. Reumatismo. 2003; 55: 123-30.

3. Punzi L. Change gout: the need for a new approach. Minerva Medica. 2017; 108: 341-9.

4. Scire CA, Rossi C, Punzi L, et al. Change gout: how to deal with this "silently-developing killer" in everyday clinical practice. Curr Med Res Opin. 2018; 34: 1411-7.

5. Zhu Y, Pandya BJ, Choi HK. Prevalence of gout and hyperuricemia in the US general population: The National Health and Nutrition Examination Survey 2007-2008. Arthritis Rheum. 2011; 63: 3136-41.

6. Elliot AJ, Cross KW, Fleming DM. Seasonality and trends in the incidence and prevalence of gout in England and Wales 1994-2007. Ann Rheum Dis. 2009; 68: 1728-33.

7. Hakoda M. Recent trends in hyperuricemia and gout in Japan. Japan Med Assoc J. 2012; 55: 319-23.

8. Chang CC, Wu CH, Liu LK, et al. Association between serum uric acid and cardiovascular risk in nonhypertensive and nondiabetic individuals: The Taiwan I-Lan Longitudinal Aging Study. Sci Rep. 2018; 8: 5234.

9. Trifiro G, Morabito P, Cavagna L, et al. Epidemiology of gout and hyperuricaemia in Italy during the years 2005-2009: a nationwide population-based study. Ann Rheum Dis. 2013; 72: 694-700.

10. Elfishawi MM, Zleik N, Karmic Z, et al. The rising incidence of gout and the increasing burden of comorbidities: A Population-based study over 20 Years. J Rheumatol. 2018; 45: 574-9.

11. Kuo CF, Grainge MJ, Zhang W, Doherty M. Global epidemiology of gout: prevalence, in- 
cidence and risk factors. Nat Rev Rheumatol. 2015; 11: 649-62.

12. Richette P, Bardin T. Gout. Lancet. 2010; 375 : 318-28.

13. Keenan RT. Limitations of the current standards of care for treating gout and crystal deposition in the primary care setting: A review. Clin Ther. 2017; 39: 430-41.

14. Pineda C, Amezcua-Guerra LM, Solano C, et al. Joint and tendon subclinical involvement suggestive of gouty arthritis in asymptomatic hyperuricemia: an ultrasound controlled study. Arthritis Res Ther. 2011; 13: R4.

15. Andres M, Quintanilla MA, Sivera F, et al. M. Silent monosodium urate crystal deposits are associated with severe coronary calcification in asymptomatic hyperuricemia: an exploratory study. Arthritis Rheumatol. 2016; 68: 1531-9.

16. Richette P, Perez-Ruiz F, Doherty M, et al. Improving cardiovascular and renal outcomes in gout: what should we target? Nat Rev Rheumatol. 2014; 10: 654-61.

17. Ndrepepa G. Uric acid and cardiovascular disease. Clin Chim Acta. 2018; 484: 150-63.

18. Borghi C, Rodriguez-Artalejo F, De Backer $\mathrm{G}$, et al. Serum uric acid levels are associated with cardiovascular risk score: A post hoc analysis of the EURIKA study. Int J Cardiol. 2018; 253: 167-73.

19. Bos MJ, Koudstaal PJ, Hofman A, et al. Uric acid is a risk factor for myocardial infarction and stroke: the Rotterdam study. Stroke. 2006; 37: 1503-7.

20. Ragab G, Elshahaly M, Bardin T. Gout: An old disease in new perspective - A review. J Adv Res. 2017; 8: 495-511.
21. Richette P, Doherty M, Pascual E, et al. 2016 updated EULAR evidence-based recommendations for the management of gout. Ann Rheum Dis. 2017; 76: 29-42.

22. Shoji A, Yamanaka H, Kamatani N. A retrospective study of the relationship between serum urate level and recurrent attacks of gouty arthritis: evidence for reduction of recurrent gouty arthritis with antihyperuricemic therapy. Arthritis Rheum. 2004; 51: 321-5.

23. Desideri G, Castaldo G, Lombardi A, et al. Is it time to revise the normal range of serum uric acid levels? Eur Rev Med Pharmacol Sci. 2014; 18: 1295-306.

24. Mantarro S, Capogrosso-Sansone A, Tuccori $\mathrm{M}$, et al. Allopurinol adherence among patients with gout: an Italian general practice database study. Int J Clin Pract. 2015; 69: 75765.

25. Doherty M, Jenkins W, Richardson H, et al. Efficacy and cost-effectiveness of nurse-led care involving education and engagement of patients and a treat-to-target urate-lowering strategy versus usual care for gout: a randomised controlled trial. Lancet. 2018; 392: 1403-12.

26. Perez-Ruiz F, Desideri G. Improving adherence to gout therapy: an expert review. Ther Clin Risk Manag. 2018; 14: 793-802.

27. Perez-Ruiz F, Moreno-Lledó A, Urionagüena I, Dickson AJ. Treat to target in gout. Rheumatology 2018; 57: i20-i26.

28. WHO. Adherence to long-term therapies. Evidence for action; 2003. Available from: https://apps.who.int/iris/bitstream/handle/10665/42682/9241545992.pdf;jsessionid Accessed: August 2019. 